Document downloaded from:

http://hdl.handle.net/10251/140251

This paper must be cited as:

Benalia, S.; Cubero, S.; Prats-Montalbán, JM.; Bernardi, B.; Zimbalatti, G.; Blasco, J. (2016). Computer vision for automatic quality inspection of dried figs (Ficus carica L.) in real-time. Computers and Electronics in Agriculture. 120:17-25.

https://doi.org/10.1016/j.compag.2015.11.002

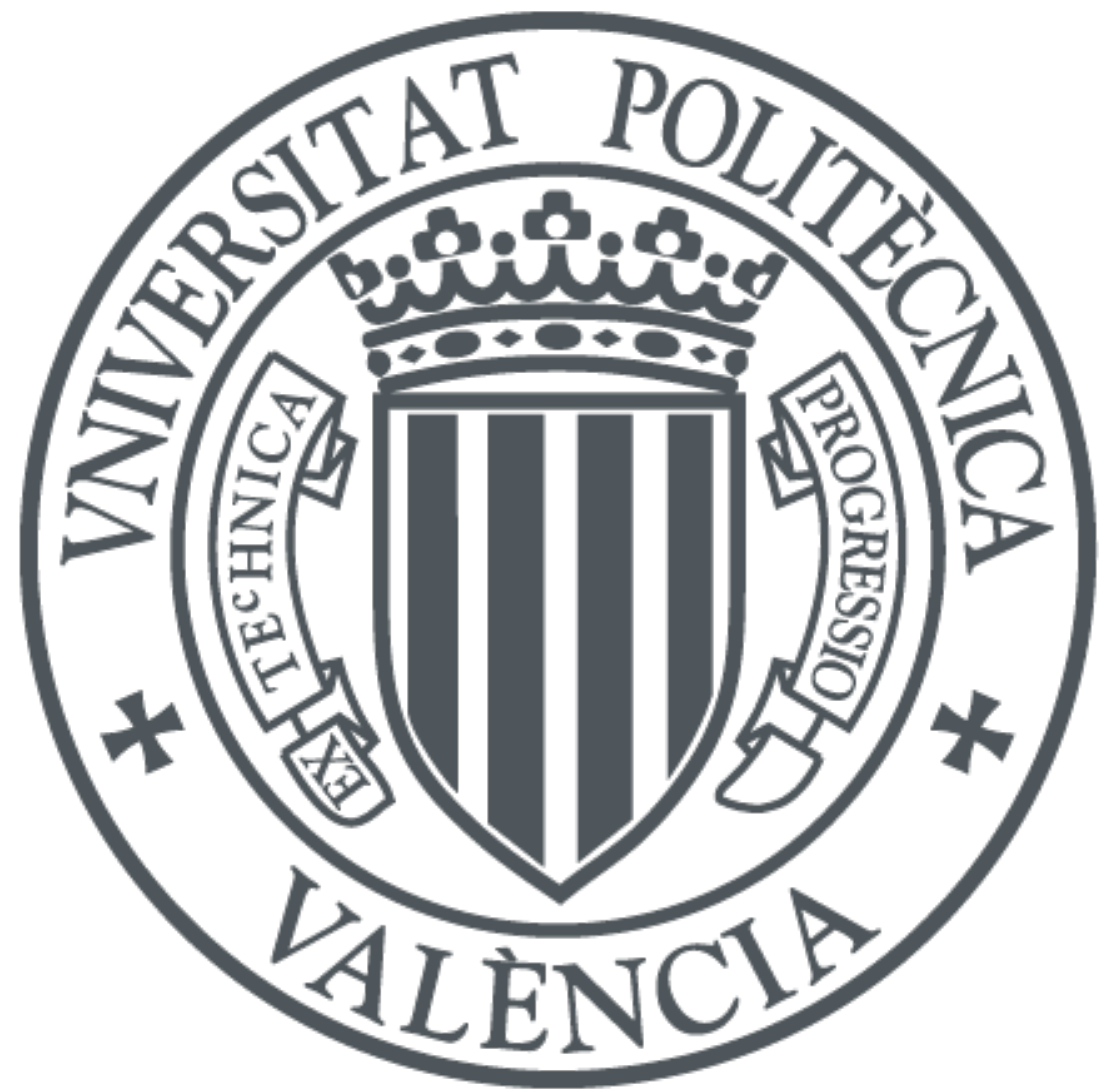

The final publication is available at

https://doi.org/10.1016/j.compag.2015.11.002

Copyright Elsevier

Additional Information 


\section{Computer vision for automatic quality inspection of dried Figs (Ficus carica}

2 L.)

3 Souraya Benalia ${ }^{\mathrm{a}}$, Sergio Cubero ${ }^{\mathrm{b}}$, José Manuel Prats-Montalbán ${ }^{\mathrm{c}}$, Bruno Bernardi ${ }^{\text {** }}$,

$4 \quad$ Giuseppe Zimbalatti ${ }^{\mathrm{a}}$, José Blasco ${ }^{\mathrm{b}}$

5 a Dipartimento di Agraria. Università degli Studi Mediterranea di Reggio Calabria, Loc. Feo

6 di Vito, 89122 Reggio Calabria, Italy,e-mail: soraya.benalia@unirc.it,

7 bruno.bernardi@unirc.it,gzimbalatti@unirc.it

$8 \quad{ }^{b}$ Centro de Agroingeniería. Instituto Valenciano de Investigaciones Agrarias (IVIA), Cra.

9 Moncada-Naquera Km 5, Moncada, Spain, e-mail: jblasco.ivia@gmail.com,

10 cubero_ser@gva.es

$11{ }^{c}$ Departamento de Estadística e Investigación Operativa. Universitat Politècnica de

12 València, Camino de Vera s/n, 46022 Valencia, Spain, ,e-mail: jopramon@eio.upv.es

\section{Abstract}

This work develops automated systems based on computer vision to improve the quality control and sorting of dried figs of Cosenza (protected denomination of origin) focusing on two research issues. The first one was based on qualitative discrimination of figs through colour assessment comparing the analysis of colour images obtained using a digital camera, with those obtained according to conventional instrumental methods, i.e. colourimetry currently done in laboratories. Data were expressed in terms of CIE XYZ, CIELAB and HunterLab colour spaces, as well as the browning index measurement of each fruit, that were analyzed using PCA and PLS-DA based methods. The results showed that both chroma meter and image analysis allowed a complete distinction between high quality and deteriorated figs, according to colour attributes. The second issue had the purpose to develop image processing algorithms to achieve real-time sorting of figs using an experimental prototype based on 
machine vision, advancing an industrial application. An extremely high 99.5\% of deteriorated figs were classified correctly as well as $89.0 \%$ of light good quality figs. Lower percentage was obtained for dark good quality figs but results were acceptable since the most of the confusion was among the two classes of good product.

Keywords: fig; image analysis; computer vision; quality; colour; post-harvest processing

\section{INTRODUCTION}

The growing attention of consumers for regional and local products and the relationship they have with their territory represents an interesting opportunity for agricultural and rural development. The promotion of these high quality food products, which can contribute considerably to rural development and agricultural diversification, could be realized through designations of origin and geographical indications labels (European Commission, 1996; De Luca et al., 2015). The designation of the protected denomination of origin (PDO) 'Fichi di Cosenza DOP' (European Commission, 2011) exclusively regards naturally dried fruits of the domestic fig "Ficus carica sativa" (domestica L.) belonging to the variety 'Dottato' or 'Ottato', and presenting specific physical, chemical and organoleptic features.

Very nutritional and healthy, dried figs constitute a popular food for local populations of the Mediterranean area because of their content in sugars, mainly fructose and glucose, in essential amino-acids, in carotene (vitamin A), thiamine (vitamin B1), riboflavin (vitamin B2), ascorbic acid (vitamin C), and minerals such as K, P, Fe, Mg, Ca and Cu. They represent an important source of fibre and their high content in phenolic compounds strongly contribute to their definition as functional fruits (Hatano et al., 2008; Farahnaky et al., 2009; Vallejo et al., 2012). Nevertheless, this strategic cultivation often remains marginalized in many rural areas, as reported by IPGRI and CIHEAM (2003), where it could contribute significantly to their sustainable development. According to FAOSTAT (www.faostat.org), fig production in 
Italy counted 11.520 tons in 2013. In the same year, and according to Istat data (National Institute of Statistics - Italy), Calabria is in second place after Campania (Southern Italy), both in terms of cultivated area (474 ha) and production with 2.839 tons, corresponding to $24 \%$ of the national total. In Calabria (Southern Italy), fig cultivation is principally located in the province of Cosenza, where the widest-grown cultivar is the 'Dottato'.

The expectations and requirements of exigent consumers lead the agro-food industries to increase the marketed product quality, extend its shelf life, reduce the environmental impact, as well as to improve the content in services, but the intrinsic biological variability between individual fruit and vegetable products make it impossible for analytical destructive methods to ensure that each individual fruit meets the high quality standards that constitute a fundamental criterion for a competitive place in a global market. Dried figs should respond to the minimum quality requirements established by UNECE (United Nations, 2014). They should be 'intact, sound, clean, sufficiently developed, free from living pests and any of their damages, free from blemishes, areas of discolouration, free from mould filaments, free of fermentation, free of abnormal external moisture and free of foreign smell and/or taste except for a slight salty taste'. Nowadays, the quality sorting of dried figs is carried out manually by experienced operators, which are usually located on both sides of conveyors belts or rollers transporting fruits to be sorted, but visual methods are slow, subjective and do not guarantee the quality of the whole production. Hence, the agro-food industry has to implement new technologies that provide rapid and reliable results, allowing at the same time a qualification of the product along the entire supply chain.

Consumer willingness to purchase often depends on the appearance of the product, which may also influence the expectations relating to the organoleptic properties, and therefore consumer behaviour. Colour perception is subjective and can be considered as an indicator of freshness or maturity state (Valadez-Blanco et al., 2007). Different physical systems have 
been developed to avoid this subjectivity for colour analysis, which may be evaluated with visual and/or instrumental procedures (González-Miret et al., 2007). In comparison, conventional instruments analyze only a small part of the sample, and therefore are not appropriate for food that often presents a heterogenic surface, and consequently, artificial vision systems have been developed in recent years in order to overcome this problem and to make colour analysis more exhaustive and meticulous including the total surface of the product while carrying out post-harvest operations (Kang \& Sabarez, 2009). In this sense, non-destructive technologies for foodstuff quality assessment such as machine vision systems constitute a promising tool for quality control as well as product inspection, sorting and grading ( Gómez-Sanchis et al., 2013;Pallottino et al., 2013a \& 2013b; Benalia et al., 2015). Indeed, images are both a large data set and a visible entity that can be interpreted at the same time (Grahn \& Geladi, 2007). Recent progress in image acquisition techniques allows areas of millions of pixels to be analysed using sophisticated systems (Martin et al., 2007).

Even though numerous studies have considered digital imaging employment for the various aspects of food colour assessment in the recent years ( Mendoza et al., 2006; Kang \& Sabarez, 2009; Menesatti et al., 2009), these latter are still at experimental scale. They certainly need to be optimized for large-scale implementation in agro-food industries due to the complexity of such structures. Computer vision systems developed to work at industrial scale are by far more complex than those limited to acquire images of static fruit using still digital cameras. The fruit is in movement and randomly oriented, the image acquisition has to be synchronised with the advance of the fruit and the decision resulting from the image processing must be provided in real time to deliver the fruit to the proper quality outlet. However if optimized for large scale implantation, they are of great interest because of the advantages they present: mainly, rapidness, effectiveness, accuracy and objectiveness; moreover, they are non destructive, do not need sample treatment, and are able to assess the whole area of the product 
despite uneven features present (Cubero et al.2011). Therefore, they allow cost and labour savings, especially when used in automated processes.

The present work deals with the assessment of dried fig skin colour comparing two analytical methods: image analyses and conventional colourimetry, analyzing PDO certified dried figs 'Fichi di Cosenza', as well as deteriorated ones. Furthermore, automated sorting of figs using an experimental prototype based on machine vision systems was developed in order to confirm the obtained results and simulate post-harvest processing at industrial scale.

\section{MATERIALS AND METHODS}

\subsection{Dried fig colour assessment}

Two groups of dried figs belonging to the variety 'Dottato' were considered for trials. The first group consisted of dried figs of excellent quality harvested during the 2012 season, provided by the Consortium of 'Fichi di Cosenza DOP' (European Commission, 2011) in Southern Italy. The second group, however, comprised purchased fruits of the same variety 'Dottato', from the previous season, which showed a certain quality loss due to major sugar crystallization, as well as to fungal and insect infestations.

Fig skin colour was first measured by means of the chroma meter CR-400 (Minolta Co., Osaka, Japan), using the CIE illuminant D65 and the $10^{\circ}$ observer standard. The instrument was calibrated using a white tile reference $\left(L^{*}=97.59, a^{*}=-0.05, b^{*}=1.65\right) . L^{*}$ value indicates lightness when it is equal to 100 , or darkness if it is equal to 0 . However, $a^{*}$ value represents the red (positive value) or green (negative value); and $b^{*}$ value constitutes the yellow (positive value) or blue (negative value) (Rodov et al., 2012). Each fruit with a mean of three measurements in different zones represented a replicate.

After the chroma meter measurements, image acquisition of each fig was performed with a digital camera Canon EOS 550D that captured images with a size of 2592 x 1728 pixels and a 
resolution of $0.06 \mathrm{~mm} /$ pixel. Lighting was provided by eight fluorescent tubes (BIOLUX 18 W/965, $6500 \mathrm{~K}$, OSRAM, Germany) placed on the four sides of a square inspection chamber in a $0^{\circ} / 45^{\circ}$ configuration. The camera was connected to a computer, and image analysis was performed according to a software specially developed for this purpose at the Laboratory of Artificial Vision for Agriculture (IVIA-Spain), which separates the objects (figs) from the background using the RGB.R value, and then converts the obtained R, G, B values from the pixels selected as figs into HunterLab space. The first step consists in the conversion of RGB values to CIE XYZ values, then, from CIE XYZ to $L, a, b$ coordinates as described by Vidal et al., (2013) and to $L^{*}, a^{*}, b^{*}$ coordinates attending the equations in HunterLab (2008), in both cases assuming a D65 (6500 K) illuminant and a $10^{\circ}$ observer.

Since RGB colour model is device dependent (Menesatti et al., 2012), a previous calibration step was done consisting in the comparison of the colour of each patch of a digital colour checker (Digital ColorChecker SG Card, X-Rite Inc, USA) acquired using the chroma meter and the camera. The colours were then converted from RGB to CIELAB and a linear regression was done between both series of values giving a $\mathrm{R}^{2}>0.98$ for the three $L^{*}, a^{*}$ and $b^{*}$ components. Hence, it was considered that the camera provided accurate colours.

\subsubsection{Data analysis}

Data obtained from both conventional colourimetry and image analysis were then expressed in terms of XYZ.X, XYZ.Y, XYZ.Z, $L^{*}, a^{*}, b^{*}, L, a, b$ coordinates, and the ratios $L / a, L^{*} / a^{*}$ in order to look for the best variables among all that permit the best segregation between both groups since that it was the first time that such analyses are done on dried figs. In addition, the browning index $(B I)$ that it is considered to be an important parameter where enzymatic or non-enzymatic browning processes occur (Mohammad et al., 2008) was also calculated and considered in the model (eq. 1, Palou et al., 1999). 


$$
\mathrm{BI}=\frac{100(\mathrm{x}-0.31)}{0.172}
$$

where:

$$
x=\frac{a+1.75 L}{5.645 L+a-3.012 b}
$$

At the end of the trial, a total of 26 parameters (variables) were obtained and statistically analyzed according to principal component analysis (PCA) and partial least squares discriminant analysis (PLS-DA), using SIMCA-P v13 (MKS Umetrics AB, Sweden). In order to compress and interpret the internal relationships between variables, and at the same time check whether there are some of these being able to segregate between the two analyzed classes (deteriorated and not deteriorated figs), principal component analysis PCA (Jackson, 1991) was applied. PCA is a projection method of the original variables onto new ones, called latent variables, orthogonal and arranged according to their explained variance. This is carried out expressing a matrix $X$ as:

$$
X=T P^{\mathrm{T}}+E
$$

where $T$ is the score matrix, $P$ is the loading matrix and $E$ is the residual matrix for $X$. This way makes it possible to determine the general pattern of any process, and the relevant variables that rule it.

However, PCA does not necessarily search for those variables that better discriminate between classes, but only for those gathering the highest variance in the data. Thus, when looking for segregating, another latent-based multivariate projection model, such as PLS-DA (Sjöström et al., 1986) is a more sensible technique to apply. PLS (Geladi \& Kowalski, 1986) models the data through the use of eq. 2 and these other following expressions:

$$
T=X W^{*}=X W P^{T} W
$$

$$
Y=T C^{T}+F
$$


where $T$ is the score matrix, $P$ the loading matrix for $X, C$ the loading matrix for $Y, W$ and $W^{*}$ weighting matrices, and $F$ the residual matrix for $Y$.

In the case of PLS-DA, $Y$ is built from as many dummy variables as classes we have to segregate. A dummy variable is a binary variable formed by 1's and 0's, the former linked to the class the dummy variable is related to, and zeros to the rest of observations. Hence, the PLS-DA looks for those internal directions that best segregate the classes of interest, also trying to explain $X$ reasonably.

This way, it is possible to compute, from any matrix $X$, the prediction of $Y$ as:

$$
Y_{\text {pred }}=X B_{P L S}=T Q^{T}=X W\left(P^{T} W\right)^{-1} Q^{T}
$$

Where

$$
B_{P L S}=X W\left(P^{T} W\right)^{-1} Q^{T}
$$

When applied to images, these techniques belong to Multivariate Image Analyses, MIA (Prats-Montalbán et al., 2011). Together they make up the most suitable analytical tools for the trials that were carried out, taking into account that each sample was considered regarding its 26 variables.

\subsection{In-line dried fig sorting}

Due to the high complexity of handling small fruit and the relatively low market in comparison to other fresh fruit, there are not commercial electronic sorters of dried figs to separate them in qualities. Hence, there is a need to develop such sorter. For this purpose, automated sorting trials based on a computer vision system were performed on an experimental prototype, developed at the Laboratory of Artificial Vision for Agriculture (IVIA-Spain) that was originally designed for mandarin orange segment and pomegranate aril in-line sorting (Blasco et al., 2009a; Blasco et al., 2009b) and that was adapted for the sorting 
of dried figs. It principally consists of three functioning elements: supply unit; inspection unit and separation unit (figure 1).

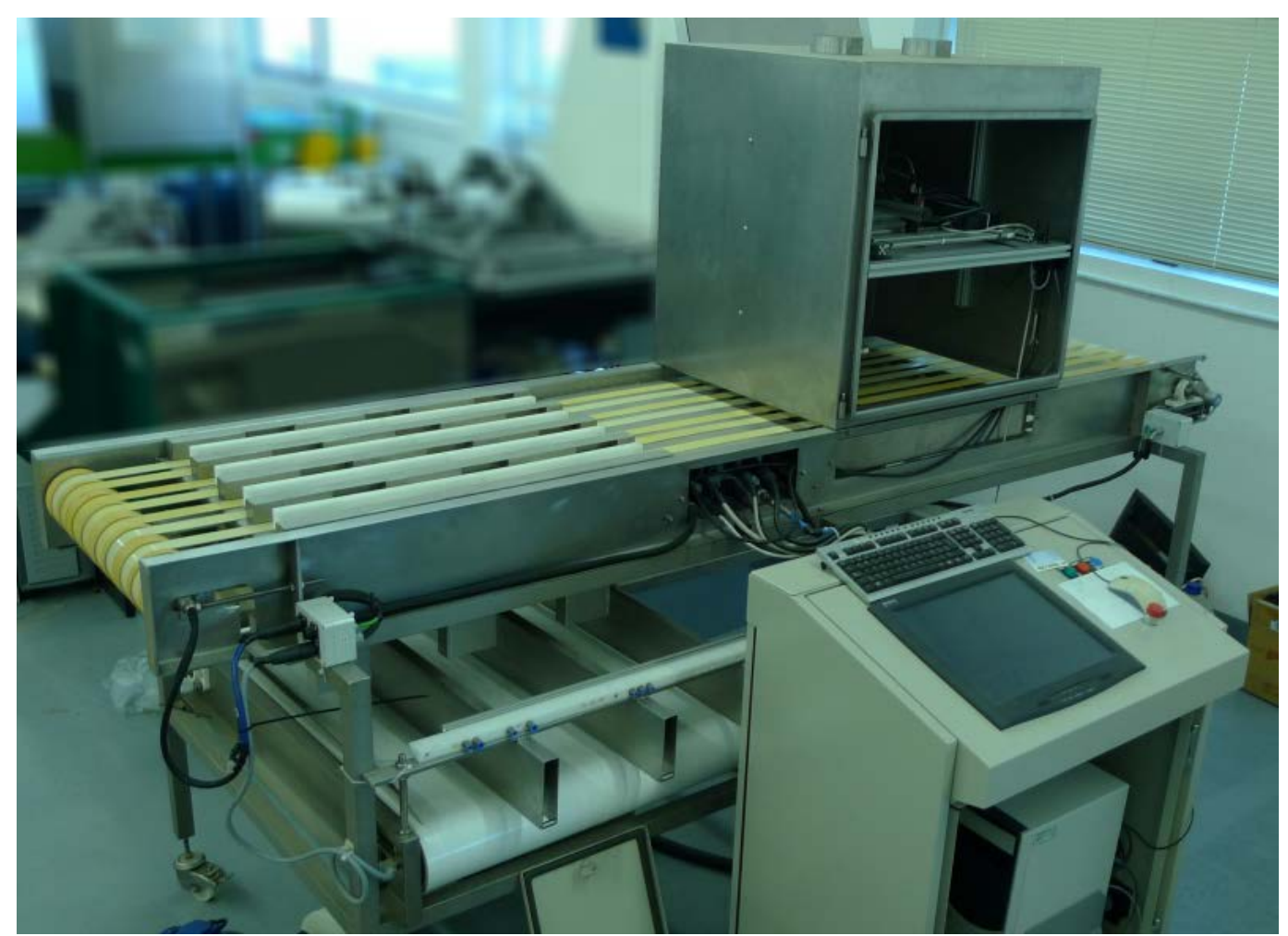

Figure 1. Picture of the in-line sorting prototype

From the supply unit, fruit are spread on a number of conveyor belts, $30 \mathrm{~mm}$ wide and 250 $\mathrm{mm}$ long, moving at a relatively high speed $(0.5 \mathrm{~m} / \mathrm{s})$. They pass through the inspection unit which consists of two progressive scanning colour cameras (JAI CV-M77), placed at approximately $0.9 \mathrm{~m}$ above the subject, that provide RGB images (512 x 384 pixels) with a resolution of $0.70 \mathrm{~mm} /$ pixel. Cameras are equipped with $12 \mathrm{~mm}$ lens, and lighting is provided by light emitting diode (LED) lamps. The entire system is housed in a frame of stainless steel suitable for agro-food products. After each image processing, the computer sends data about: fruit position, the number of the conveyor belt on which it is located, and the corresponding category (issue) to the computer which is responsible for directing the movement of the inspected fruit to the separation unit and its subsequent categorisation. 
The trials considered 96 figs, which had previously been classified in the subsequent three categories: 31 light PDO figs, 26 dark PDO figs and 39 deteriorated figs (figure 2). Each fruit in the validation set went through the whole classification process five times in random positions, orientations and sides, thus it was as if 480 figs were categorised. An additional set of 24 figs was used to build the models and train the image processing software.

One of the requirements of current quality standards for dried figs is that the contents of each package must be uniform (United Nations, 2014). Moreover, consumers are prone to purchase lots with uniformity of colours and sizes. Hence, the output of each category was established as follows:

- Category 0: (Light PDO figs): the fig arrives at the end of the conveyor belt.

- Category 1: (Dark PDO figs): the fig is ejected at the first outlet.

- Category 2: (Deteriorated figs): the fig is ejected at the second outlet.

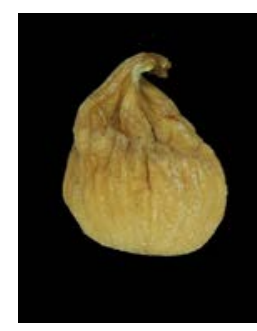

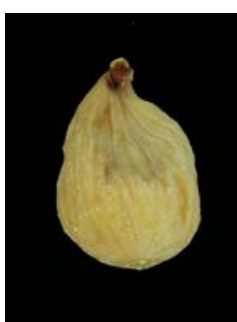

a)
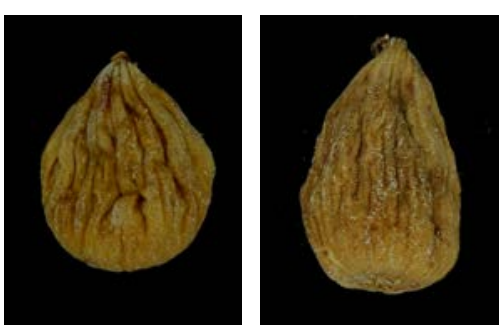

b)
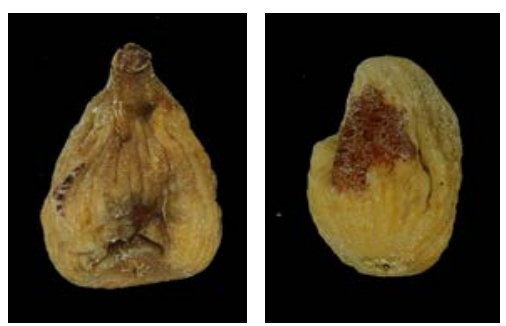

c)

Figure 2. Samples with different colours that should belong to different categories: a) light, b) dark and c) defective uneven coloured figs

In-line systems working in real-time have to run very fast image processing algorithms and hence it is not possible to incorporate complex segmentation models although it could be more effective in some cases. On the other hand, it is very important that the quality parameters can be easily controlled by non-experienced workers trough a friendly interface. This means that, the machine has to prioritize easy to handle methods to separate the fruits over other maybe more robust but also more complex statistical methods. 
227 Following this principle, image segmentation was developed based on the analysis of the colour that was done on images captured with the mentioned industrial cameras under dynamic conditions. As first step, each pixel in the image was classified as background or as belonging to an object to be analysed. Since there was a great contrast between the white background and the fruit, a threshold was enough to properly remove the background from the image analysis. Preliminary analysis of the histogram of the training images determined that a threshold value of $T_{0}=100$ in the green band could separate the fruit without error. Therefore, any pixel with a value in the $\mathrm{G}$ channel above $T_{0}$ could be considered as belonging to the background and removed. This operation was performed only in the regions of interest corresponding to the conveyor belts while the parts of the images outside these regions were not considered.

All remaining pixels in the images were considered as belonging to potential figs. Therefore, the RGB values of the remaining pixels were converted into CIE XYZ and CIELAB coordinates to calculate the $B I$.

To separate the pixels in the figs into any of the predefined classes it was necessary a previous analysis. An analysis of the variance (ANOVA) was carried out for each variable using the training samples to determine in which of the different available colour coordinates the figs that belonged to different qualities could be better discriminated, or if it was necessary, a combination of several colour coordinates. Once defined the variables, the thresholds among the three classes initially set in the sorting prototype were established from the data extracted the basic statistics (tables 3 and 4). Once determined the colour indexes and the thresholds, the algorithms were programmed to classify the pixels in the images in one of the three categories as follows, where the thresholds $T_{1}$ and $T_{2}$ were obtained from the previous analysis: 
- If average $B I<T_{1}$ the pixel was considered deteriorated

- If average $B I \geq T_{1}$ and average $X Y Z . X<T_{2}$, the pixel was considered a dark PDO; otherwise the pixel was considered as belonging to a fair PDO fig.

After the pixels-wise image segmentation, it was necessary to perform a filtering process in order to reduce the noise caused by shadows found in the borders of the fig and by small groups of isolated pixels. This process consisted on a two-iteration erosion of the complete fig followed by a median filter. Finally, the decision about the category of the fig was set based on the number of pixels of each class belonging to the fig, which is equivalent to classify the fig into the class occupying the major area in the fig.

The sequence of image processing carried out by the sorting machine in real time is shown in figure 3. The original image captured by the cameras shows the figs while they are transported by the conveyor belts. The first step corresponds to the segmentation based on the thresholds in the regions of interest defined by the known position of the conveyor belts. Then the filtering is performed in order to reduce the noise and the segmentation problems caused by shadows found in the borders of the figs. Finally, the decision is taken by counting the amount of pixels belonging to the different classes. For the case shown in figure 3, attending the decision of the vision system, the figs in blue belonged to the deteriorated class, the figs in red are dark figs, and the fig in green is a light one.
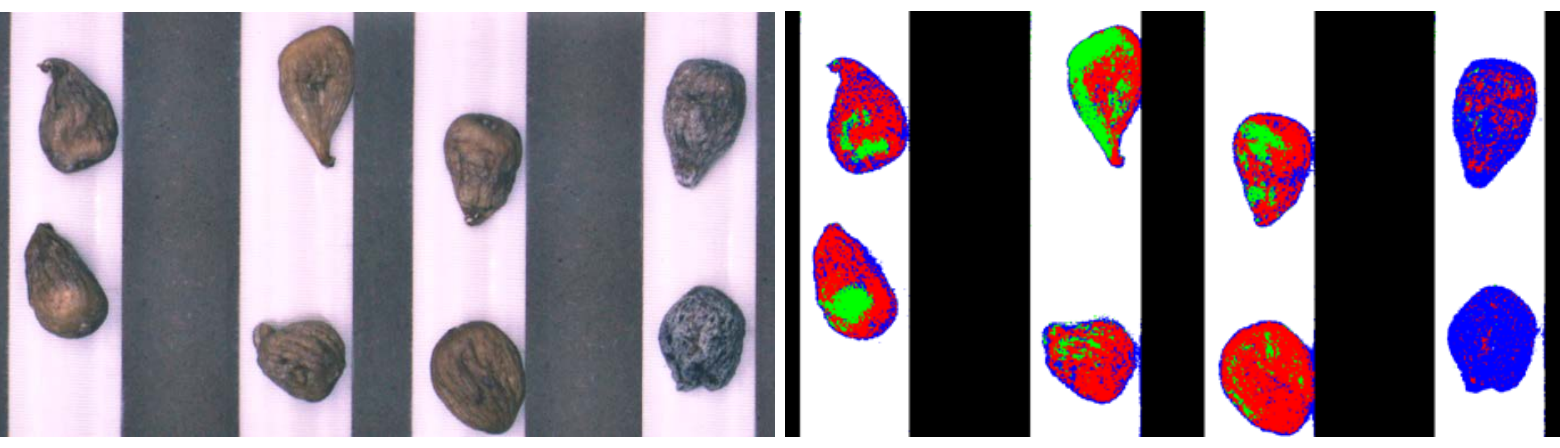

a)

b) 


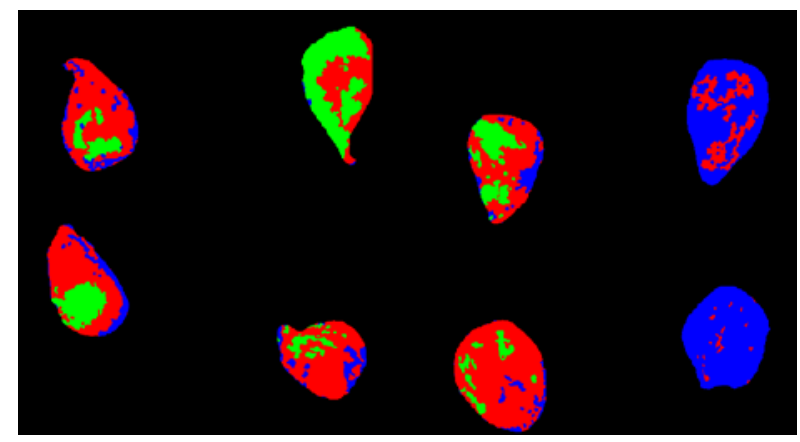

C)

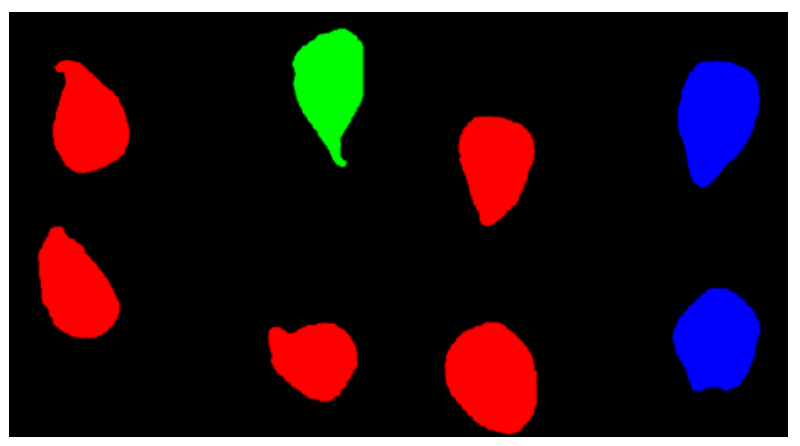

d)

Figure 3. Steps in-line image processing of the figs sorting machine. A) original image captured by the cameras, b) segmented image, c) filtered image, and d) decision image

The tests were carried out by placing the figs into a vibrating platform that guide the fruit randomly to the different conveyor belts of the prototype. Each fruit was transported by the conveyor belts, analysed and sorted by the outlet corresponding to their assigned category. This was done for the different categories of fruit separately for a proper identification and reference of the fruit once it was separated in the outlets, since it would be difficult to properly identify each individual fruit in the outlets after being sorted by the machine if all of the figs would had been tested in the same trial. After each trial, the fruit in the different outlets was accounted and tested again for five times.

\section{RESULTS AND DISCUSSION}

\subsection{Dried Fig colour assessment}

Figure 4 represents the score plot of PCA (2 PC's, R² 81\%), showing an overview of the behaviour of each fruit belonging to the studied groups with PDO figs of Cosenza in black and deteriorated ones in red. Here, as stated above, the analysis considered the totality of variables (26), that is, those obtained by conventional colourimetry as well as those obtained from image processing. In this case, the PCA model is able to segregate the two classes. In 

5) is inspected.

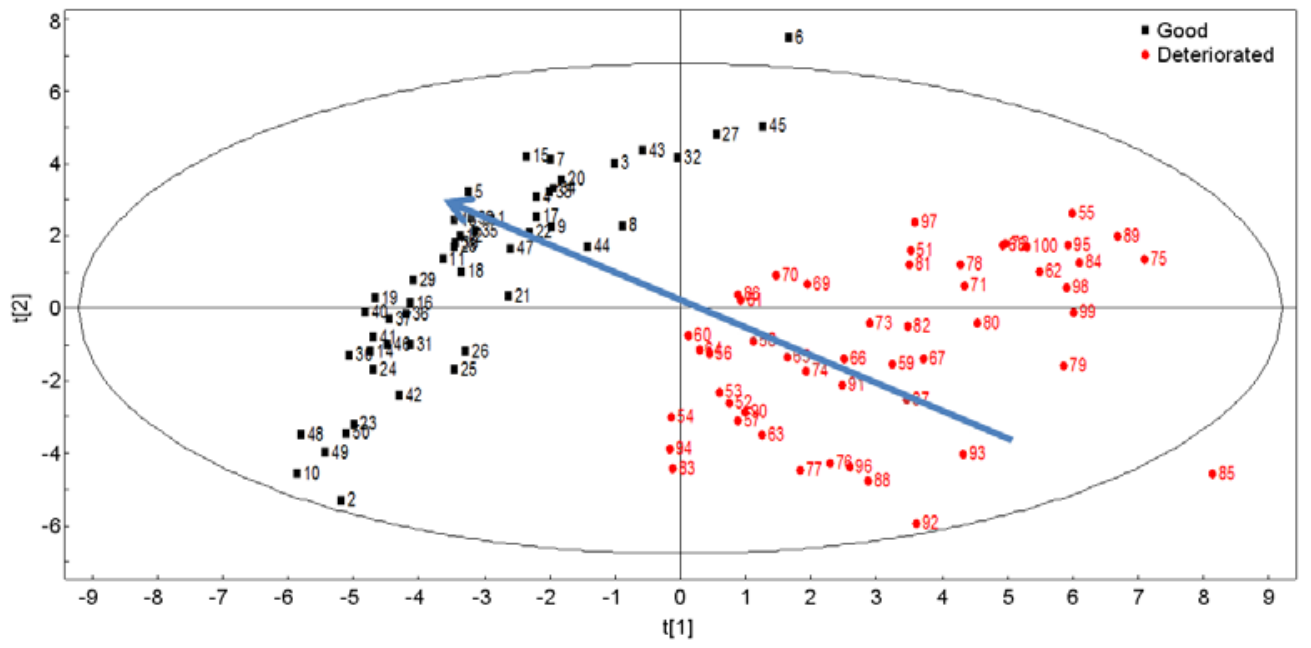

292

Figure 4. Score plot of PCA results considering all the variables (image analysis and conventional

294 colorimetry). The ellipse represents 95\% confidence interval.

295 The segregation between class 1 (sound figs represented by black points) and class 2

296 (deteriorated figs represented by red points) is mainly characterized by the variables

297 XYZ.Zcol, XYZ.Zimg and L/a on one hand, and CIEb_img, Huntb_col, and CIEb_col, on the 298 other hand.

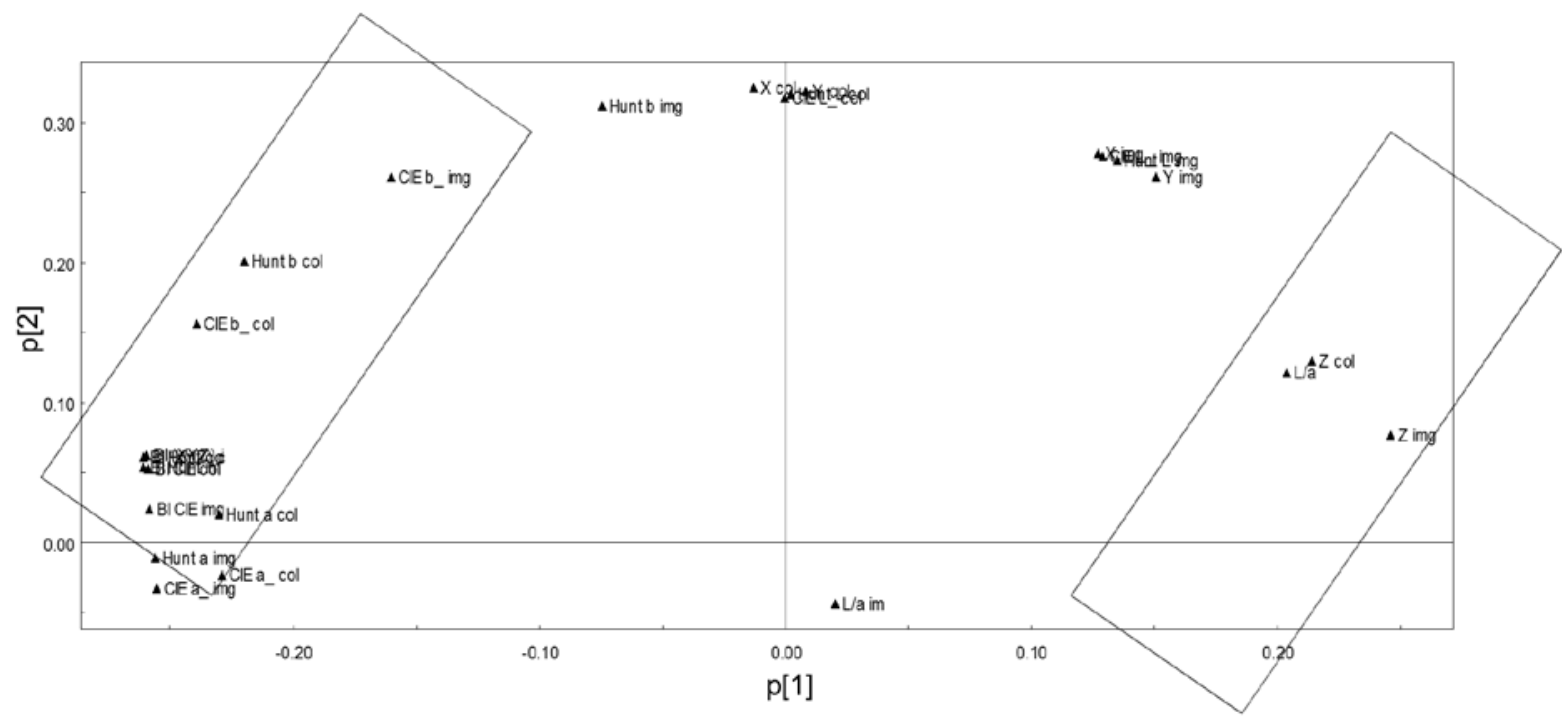


Figure 5. Loading plot of PCA results considering all the variables (image analysis and conventional colorimetry). The rectangles include the most segregating variables.

PLS-DA results highlight two clusters, each one corresponding to one of the assessed groups of figs (figure 6). The plot shows that the first component is able to segregate between the two classes. From the PLS-DA weights of the first component (figure 7), the variables responsible for the segregation can be derived. Note that, in the case of having more than one discriminant component in the model, other approaches (e.g. VIP's) would be more sensible. Nevertheless, in this case, since the discriminant direction is mainly related to the fist latent variable, both approaches provide equivalent results (see figure 8), with the advantage that the weights provide the positive or negative correlation of each variable with each of the classes to be segregated. It must be stated that, for classification purposes, the model was built with 5 latent variables and an R2Y value of 96.5\% and a Q2Y value of 95\%, which in practice means that all figs where correctly classified in a 7-blocks cross-validation procedure. However, this was not the goal of the analysis, but selecting the most discriminant variables and comparing them with the ones used in the already built in-line sorting machine.

On the other hand, the score plots of PCA and PLS-DA show similar clusters for the two studied groups, and PCA confirms that the XYZ.Z coordinate is one of the best discriminant variables. The difference between the two score plots lies in the fact that PCA does not look for segregating both classes, but for maximizing the variance, as previously stated. Anyway, since the rotation in the components is not very large, the variables indicated by the loadings barplot (figure 9) are almost the same as the ones outlined by the first component weights of the PLS-DA model (figure 7). 


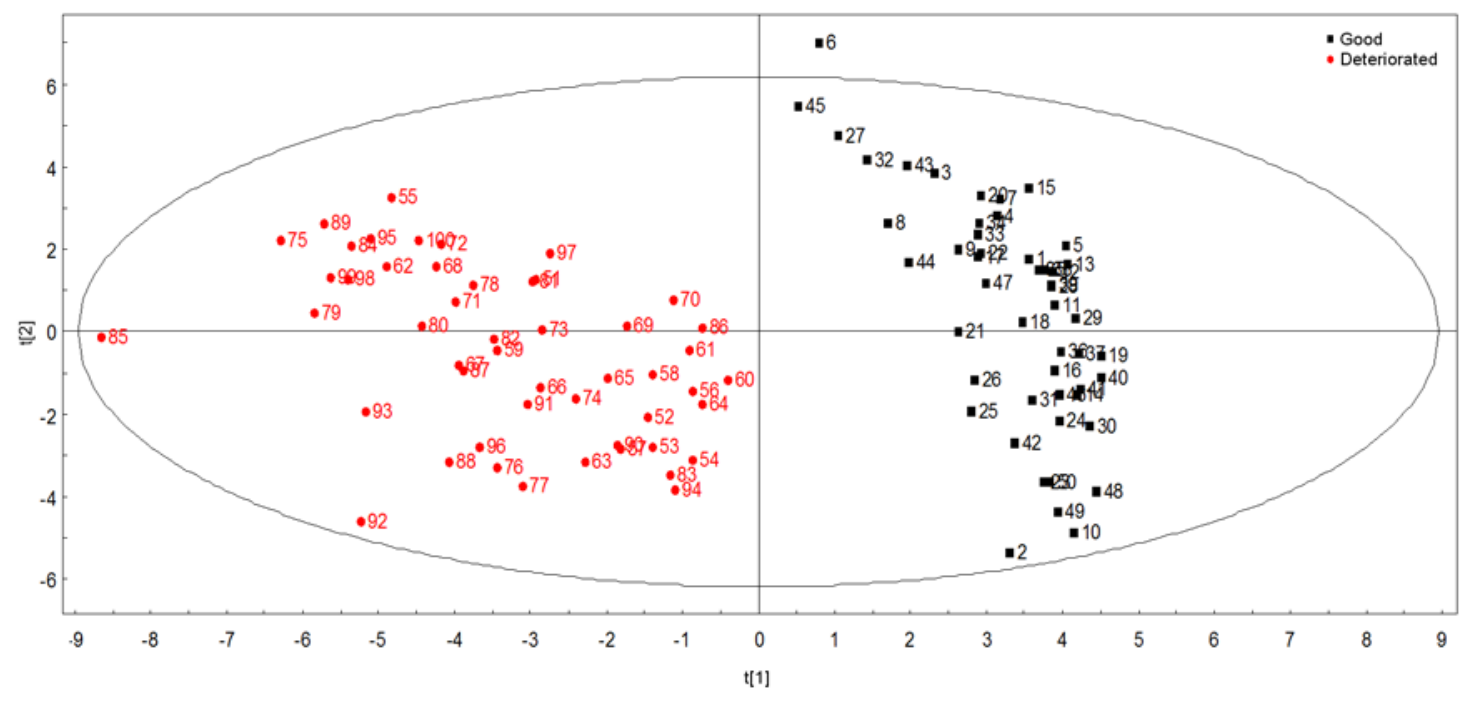

323 Figure 6. Score plot of PLS-DA results considering all the variables (image analysis and conventional colorimetry). The ellipse represents 95\% confidence interval.

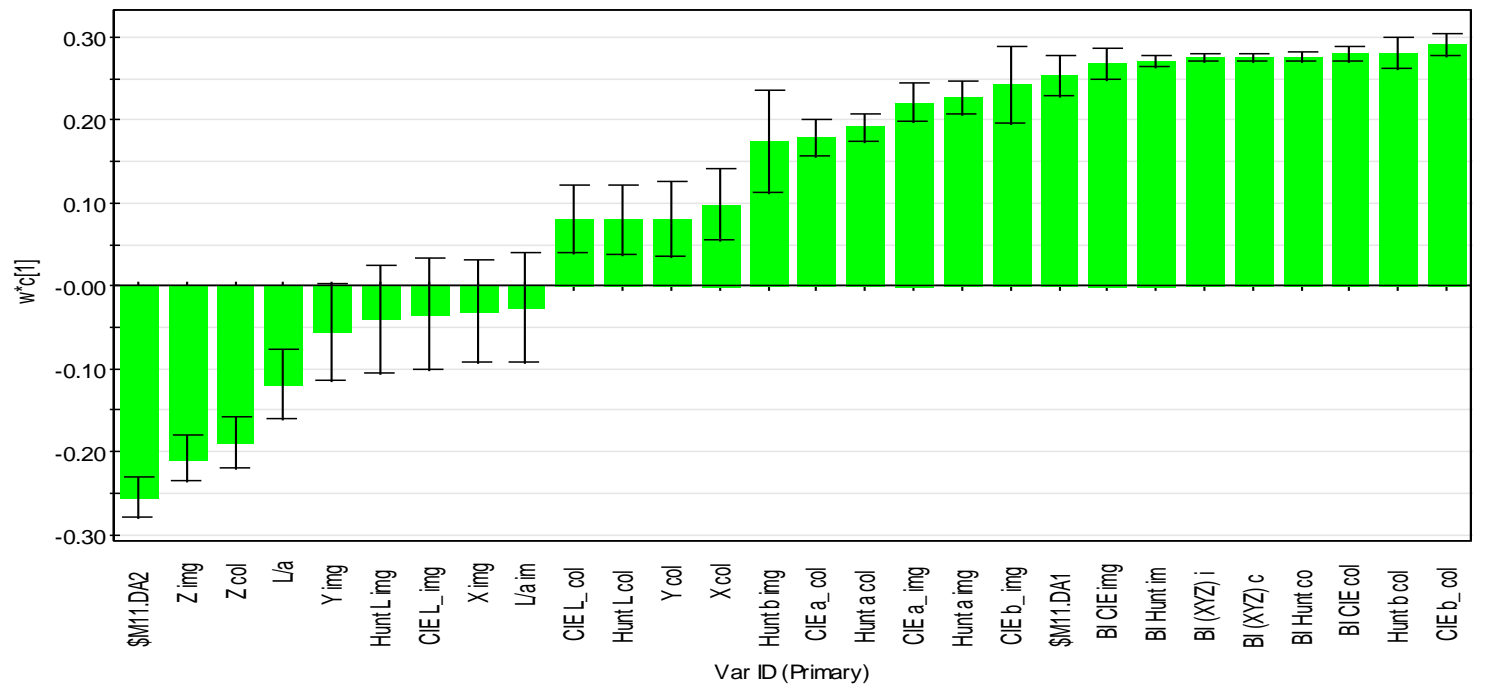

326 Figure 7. Weights plot of the first component of the PLS-DA model considering all the variables

327 (image analysis and conventional colorimetry) 


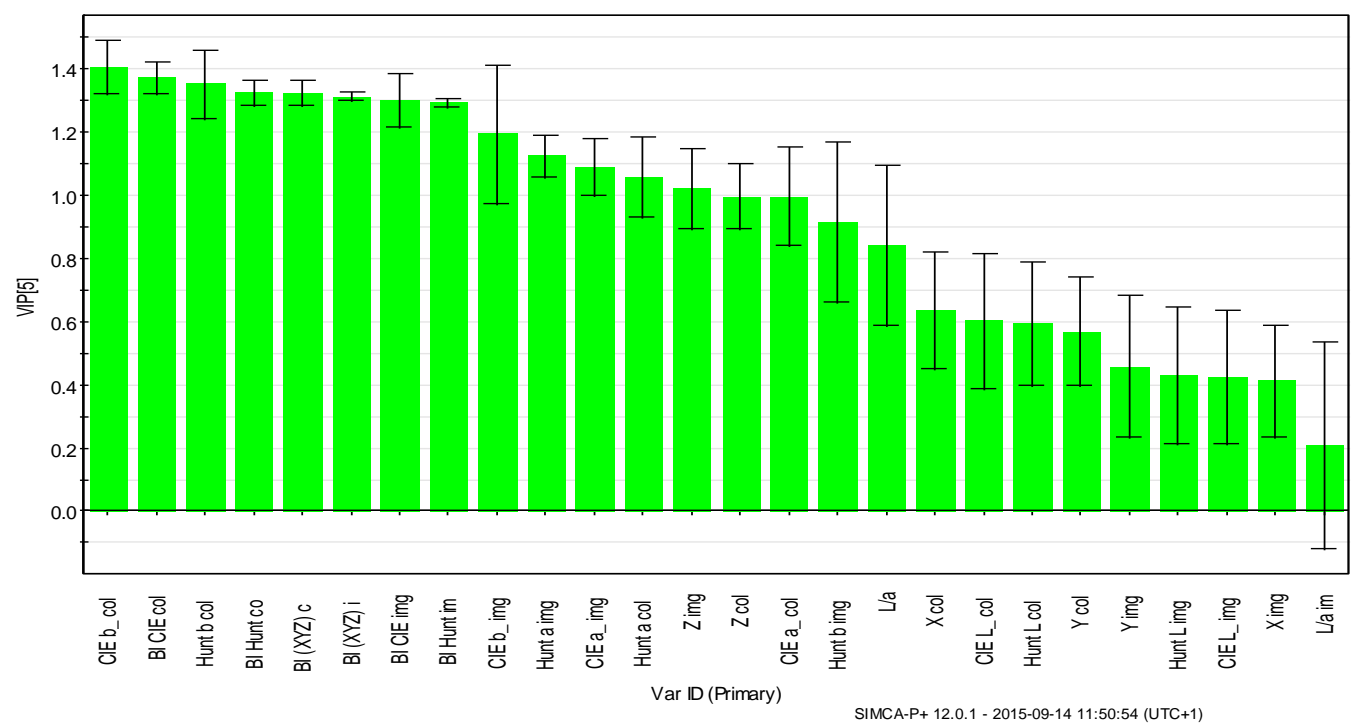

Figure 8. VIP's plot of the first component of the PLS-DA model considering all the variables

(image analysis and conventional colorimetry)

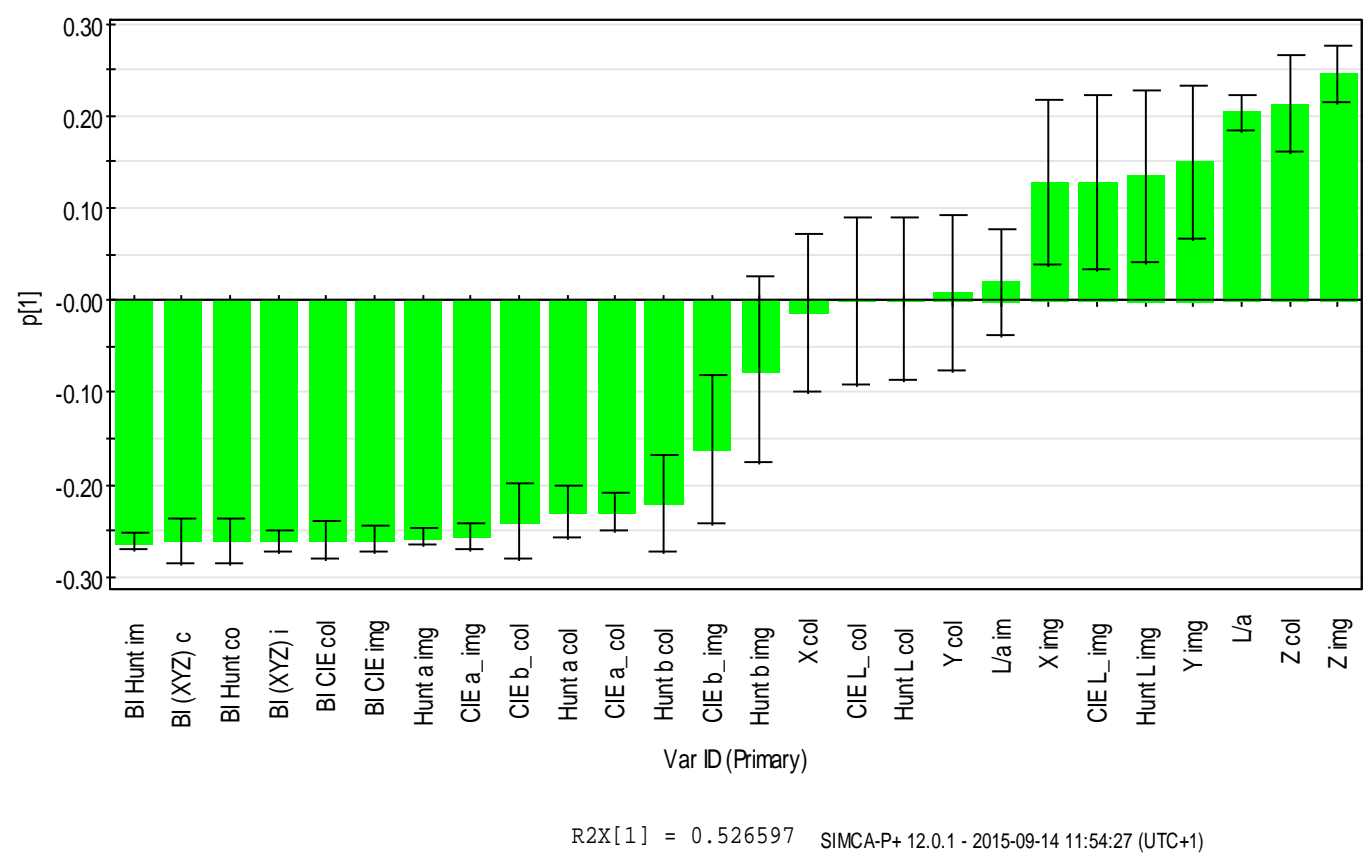

332 Figure 9. Columns plot of PCA for the first component considering all the variables (image analysis and conventional colorimetry)

334 The study carried out highlights that, in this case, both statistical analyses, PCA and PLS-DA, could distinguish clearly between high quality PDO figs and deteriorated ones, showing the effectiveness of both techniques used for fig colour assessment as a qualitative parameter.

337 Hence, analysis of high quality images could perfectly replace currently destructive methods 
based on sampling for this purpose. The browning index seemed to be an interesting index that showed this distinction, and therefore a valid indicator for dried fig quality assessment but the colour measurement in some different spaces did not present significant differences. Nevertheless, note that, depending on the study, the discriminant directions in PCA (if any) might not be necessarily on the first components, hence being mandatory to look for them throughout the ones gathered in the model (Prats-Montalbán et al., 2006).

\subsection{In-line dried fig sorting}

The methods, conditions, aims and equipment used for classifying the fruit in real-time using and industrial machine are different from those used to assess colour using a standard colorimeter and hence new variables need to be selected. ANOVA's carried out on the main discriminant variables highlighted by the PLS-DA and PCA analyses achieved similar results in terms of significance. From these analyses, variables $B I$ and $X$ were selected for segregating the different categories of figs during the in-line real-time inspection using the machine since the study of the basic statistics clearly determined that it was possible to set thresholds to separate among the different categories. Tables 1 and 2 show the ANOVA for these variables while tables 3 and 4 show the summary of the statistics. Browning index could be clearly used to separate between good and defective figs and it was decided from these data to use a threshold value of $T_{1}=35$. On the other hand, dark and light figs could be separated using the $X$ colour value and hence, using the data in table 4 , a threshold value of $T_{2}=7$ was configured in the machine.

Table 1. Analysis of variance for Browning Index

\begin{tabular}{|llllll|}
\hline Source & Sum of Squares & Df & Mean Square & F-Ratio & P-Value \\
Between groups & 9435.52 & 2 & 4717.76 & 83.03 & 0.0000 \\
Within groups & 5284.36 & 93 & 56.82 & & \\
\hline
\end{tabular}




Total (Corr.) $14719.90 \quad 95$

359

Table 2. Analysis of variance for $X$

\begin{tabular}{|llllll|}
\hline Source & Sum of Squares & Df & Mean Square & F-Ratio & P-Value \\
Between groups & 311.73 & 2 & 155.86 & 53.48 & 0.0000 \\
Within groups & 271.04 & 93 & 2.91 & & \\
Total (Corr.) & 582.77 & 95 & & & \\
\hline
\end{tabular}

361

362 Table 3. Summary Statistics for Browning Index

\begin{tabular}{|c|c|c|c|c|c|}
\hline Class & Averag & Standard deviation & Coeff. of $v$ & Min & $\operatorname{Max}$ \\
\hline Light & 48.27 & 5.43 & $11.24 \%$ & 36.58 & 59.54 \\
\hline Dark & 43.13 & 8.43 & $19.90 \%$ & 31.56 & 61.71 \\
\hline Deteriorated & 25.93 & 8.31 & $32.04 \%$ & 8.48 & 41.70 \\
\hline
\end{tabular}

363

Table 4. Summary Statistics for $X$

\begin{tabular}{|lccccc|}
\hline Class & Average & Standard deviation & Coeff. of variation Min & Max \\
Light & 8.81 & 1.89 & $21.78 \%$ & 6.32 & 14.53 \\
Dark & 5.63 & 0.90 & $15.90 \%$ & 4.08 & 7.75 \\
Deteriorated & 10.08 & 1.94 & $19.26 \%$ & 5.56 & 13.15 \\
\hline
\end{tabular}

365

366 Results of the performance of the machine are shown in table 5. At the end of the trials,

$36799.5 \%$ of deteriorated figs were correctly classified, as well as 89\% of light PDO figs;

368 however, just $69.2 \%$ of accurate classification was reached for dark PDO figs. This decrease

369 of accuracy is related to the unevenness of the figs' skin colour. In fact, some fruits had a

370 lighter colour on one side than on the other; consequently, the machine classified them 
according to the colour of the side showing as they randomly passed. It has to be remarked that the results correspond to the inspection of the validation set of the figs five times, but each time they fall down in a random position, orientation and side on the conveyor belts and were captured in a different and random location in the image. This means that for each time, the conditions and lighting of each particular fig were different.

A certain degree of confusion is normal using the fast classification method implemented. However, the main confusion occurred between classes light and dark which could be acceptable since both are good quality figs separated only for commercial reasons. On the other hand, a little confusion happened between good and deteriorated figs that are more important from the point of view of the final quality. An aspect to improve is that the machine classified 3.8\% deteriorated figs as dark, which, even it could be under a tolerance of $5 \%$, should be reduced. On the contrary, it would be of less importance if dark figs were classified as deteriorated. These results illustrate that fig sorting, using the above-described system, was achieved successfully. The highest percentage was obtained each time for deteriorated figs, followed by light PDO ones, and then dark PDO figs.

Table 5. Results of automated sorting

\begin{tabular}{|llll|}
\hline Machine $\backslash$ Vis & Light PDO figs & Dark PDO figs & Deteriorated figs \\
Light PDO figs & $89.0 \%$ & $26.9 \%$ & $0.5 \%$ \\
Dark PDO figs & $11.0 \%$ & $69.2 \%$ & $0.0 \%$ \\
Deteriorate figs & $0.0 \%$ & $3.8 \%$ & $99.5 \%$ \\
\hline
\end{tabular}

To identify a specific index to determine accurately the quality for PDO dried figs of Cosenza, the achieved analysis has to be consolidated by further research, taking into account additional parameters i.e., colour change according to ripeness, drying status as well as the 
correlation of skin colour with the contents of anthocyanins (Rodov et al., 2012). This may be achieved and incorporated in the future to the in-line sorting machine with the use of faster computing units.

Some of the problems found could be resolved using, instead of conveyer belts, bi-conic roller conveyors (ElMasry et al., 2012) which turn the fruits as they progress, allowing the system to inspect their whole surface. On the other hand, a complex analysis of the colour or the texture of the figs would result in a better accuracy of the classification, but the computing requirements would not ensure actual real-time processing at a commercial speed.

Image processing time was about $15 \mathrm{~ms}$, permitting an analysis of up to 65 images/s.

However, due to mechanical limitations of the prototype, and also because a very high speed could damage the product when it is expelled by the outlets, the speed of the conveyor belts was limited to $0.5 \mathrm{~m} / \mathrm{s}$, obtaining then 10 analysed images per second. Considering an ideal distance of $0.1 \mathrm{~m}$ between two consecutive figs, at the highest speed of the conveyor belts $(0.5 \mathrm{~m} / \mathrm{s})$, the tested prototype has the productivity of about 40 figs/s, corresponding approximately to $2160 \mathrm{~kg} /$ hour. The system has been proved on a prototype with several mechanical limitations, it is expected that the performance in terms of accuracy and capacity of fruit process is higher when the system will be developed into an industrial machine.

\section{CONCLUSIONS}

As currently carried out, dried fig inspection and grading methods are labour intensive and unreliable due to machine speed and inspector fatigue. Therefore, the development of an effective integrated inspection system that can detect quality according to previously established parameters of the whole fruit would be valuable for the fig industry. The present work showed that the combination of computer vision systems and latent-based multivariate statistical projection models used for this purpose allowed these objectives to be reached 
under laboratory conditions for manual quality inspection which can be suitable for small productions or when only the control of a few number of samples is required. These results are interesting because they illustrated that both, chroma meter and image analysis allowed an effective distinction between high quality dried figs and deteriorated ones, based on colour parameters, being the photographic camera much cheaper and easy to use than the chroma meter.

A system for in-line sorting of figs in real-time was developed based on computer vision and colour parameters providing reliable results. This is the first attempt to create a machine capable of sorting dried figs in real-time using computer vision and a machine with capability of separating the fruit into different categories. The system could classify correctly between three classes of figs using the browning index and the $X$ colour coordinate. The test were carried out in dynamic conditions with the figs being transported under the camera at high speed, and later separating the figs into different categories by different outlets depending on the decision of the vision system. This was repeated five times achieving always good results, having the major confusion between the two classes of sound figs but a little confusion of only $0.5 \%$ was done between sound and defective figs which is the most important from the commercial point of view.

\section{Acknowledgement}

This work has been partially funded by INIA through research project RTA2012-00062-C0401 with the support of European FEDER funds.

\section{REFERENCES}

Benalia, S., Bernardi, B., Cubero, S., Leuzzi, A., Larizza, M., \& Blasco, J. (2015).

Preliminary trials on Hyperspectral Imaging Implementation to Detect Mycotoxins in Dried Figs. Chemical Engineering Transaction, 44, 157- 162. doi: 10.3303/CET1544027 
Blasco, J., Aleixos, N., Cubero, S., Gómez-Sanchís, J., \& Moltó, E. (2009a). Automatic sorting of satsuma (Citrus unshiu) segments using computer vision and morphological features. Computers and Electronics in Agriculture, 66(1), 1-8.

doi:10.1016/j.compag.2008.11.006

Blasco, J., Cubero, S., Gómez-Sanchís, J., Mira, P., \& Moltó, E. (2009b). Development of a machine for the automatic sorting of pomegranate (Punica granatum) arils based on computer vision. Journal of Food Engineering, 90(1), 27-34. doi:10.1016/j.jfoodeng.2008.05.035

Cubero, S., Aleixos, N., Moltó, E., Gómez-Sanchis, J., \& Blasco, J. (2011). Advances in Machine Vision Applications for Automatic Inspection and Quality Evaluation of Fruits and Vegetables. Food and Bioprocess Technology, 4(4), 487-504. doi:10.1007/s11947-010-04118

De Luca, A.I., Molari, G., Seddaiu, G., Toscano, A., Bombino, G., Ledda, L., Milani, M., Vittuari, M. (2015b). Multidisciplinary and innovative methodologies for sustainable management in agricultural systems. Environmental Engineering and Management Journal, 14 (7), 1571-1581.

Elmasry, G., Cubero, S., Moltó, E., \& Blasco, J. (2012). In-line sorting of irregular potatoes by using automated computer-based machine vision system. Journal of Food Engineering, 112(1-2), 60-68. doi:10.1016/j.jfoodeng.2012.03.027

European Commission. (1996). Commission approves the registration of agricultural and food products. Retrieved from http://europa.eu/rapid/press-release_IP-96-492_en.htm

European Commission. (2011). Commission Implementing Regulation (EU) No 596/2011 of 7 June 2011 entering a name in the register of protected designations of origin and protected 
geographical indications [Fichi di Cosenza (PDO)]. OJ L 162, 22/06/2011, 1-2. Retrieved from http://eur-lex.europa.eu/legal-content/EN/TXT/PDF/?uri=CELEX:32011R0596\&rid=4

Farahnaky, A., Ansari, S., \& Majzoobi, M. (2009). Effect of glycerol on the moisture sorption isotherms of figs. Journal of Food Engineering, 93(4), 468-473. doi:10.1016/j.jfoodeng.2009.02.014

Geladi, P., Kowalski, B.R. (1986). Partial Least-Squares Regression: A Tutorial. Analytica Chimica Acta, 185, 1-17.

Gómez-Sanchis, J., Blasco, J., Soria-Olivas, E., Lorente, D., Escandell-Montero, P., MartínezMartínez, J. M., Aleixos, N. (2013). Hyperspectral LCTF-based system for classification of decay in mandarins caused by Penicillium digitatum and Penicillium italicum using the most relevant bands and non-linear classifiers. Postharvest Biology and Technology, 82, 76-86. doi:10.1016/j.postharvbio.2013.02.011

González-Miret, M. L., Ayala, F., Terrab, A., Echávarri, J. F., Negueruela, a. I., \& Heredia, F. J. (2007). Simplified method for calculating colour of honey by application of the characteristic vector method. Food Research International, 40(8), 1080-1086. doi:10.1016/j.foodres.2007.06.001

Grahn, H. F., \& Geladi, P. (2007). Techniques and Applications of Hyperspectral Image Analysis. John Wiley \& Sons, Ed., vol. 22. doi:10.1002/9780470010884

Hatano, K., Kubota, K., \& Tanokura, M. (2008). Investigation of chemical structure of non protein proteinase inhibitors from dried figs. Food Chemistry, 107(1), 305-311. doi:10.1016/j.foodchem.2007.08.029

HunterLab. (2008). Applications note, 8(9), available at: https://support.hunterlab.com/hc/enus/articles/203997085-Hunter-L-a-b-Color-Scale-an08-96a. Last accessed: August 2015. 
IPGRI, \& CIHEAM. (2003). Descriptors for fig. International Plant Genetic Resources Institute, Rome, Italy, and International Centre for Advanced Mediterranean Agronomic Studies, Paris, France. Retrieved from http://www.ipgri.cgiar.org/

Jackson, J.E. (1991). A User’s Guide to Principal Components. New York: Wiley.

Kang, S. P. P., \& Sabarez, H. T. T. (2009). Simple colour image segmentation of bicolour food products for quality measurement. Journal of Food Engineering, 94(1), 21-25. doi:10.1016/j.jfoodeng.2009.02.022

Martin, M. L. G.-M., Ji, W., Luo, R., Hutchings, J., \& Heredia, F. J. (2007). Measuring colour appearance of red wines. Food Quality and Preference, 18(6), 862-871. doi:10.1016/j.foodqual.2007.01.013

Mendoza, F., Dejmek, P., \& Aguilera, J. M. (2006). Calibrated color measurements of agricultural foods using image analysis. Postharvest Biology and Technology, 41(3), 285295. doi:10.1016/j.postharvbio.2006.04.004

Menesatti, P., Zanella, A., D'Andrea, S., Costa, C., Paglia, G., Pallottino, F. (2009). Supervised multivariate analysis of hyper-spectral NIR images to evaluate the starch index of apples. Food and Bioprocess Technology, 2(3), 308-314. DOI: 0.1007/s11947-008-0120-8

Menesatti, P., Angelini, C., Pallottino, F., Antonucci, F., Aguzzi, J., Costa, C. (2012) RGB color calibration for quantitative image analysis: The "3D Thin-Plate Spline" warping approach. Sensors, 12, 7063-7079

Mohammad, A., Rafiee, S., Emam-Djomeh, Z., \& Keyhani, A. (2008). Kinetic Models for Colour Changes in Kiwifruit Slices During Hot Air Drying. World Journal of Agricultural Sciences, 4(3), 376-383. 
Pallottino, F., Costa, C., Antonucci, F., Menesatti, P. (2013). Sweet cherry freshness evaluation through colorimetric and morphometric stem analysis: Two refrigeration systems compared. Acta Alimentaria, 42, 428-436

Pallottino, F., Menesatti, P., Lanza, M.C., Strano, M.C., Antonucci, F., Moresi, M. (2013). Assessment of quality-assured Tarocco orange fruit sorting rules by combined physicochemical and sensory testing. Journal of the Science of Food and Agriculture, 93, 1176,1183

Palou, E., López-Malo, A., Barbosa-Cánovas, G. V, Welti-Chanes, J., \& Swanson, B. G. (1999). Polyphenoloxidase Activity and Color of Blanched and High Hydrostatic Pressure Treated Banana Puree. Journal of Food Science, 64(1), 42-45. doi:10.1111/j.13652621.1999.tb09857.x

Prats-Montalbán, J. M., de Juan, A., \& Ferrer, A. (2011). Multivariate image analysis: A review with applications. Chemometrics and Intelligent Laboratory Systems, 107(1), 1-23. doi:10.1016/j.chemolab.2011.03.002

Prats-Montalbán, J. M., Ferrer, A., Malo, J. L., \& Gorbeña, J. (2006). A comparison of different discriminant analysis techniques in a steel industry welding process. Chemometrics and Intelligent Laboratory Systems, 80(1), 109-119. doi:10.1016/j.chemolab.2005.08.005

Rodov, V., Vinokur, Y., \& Horev, B. (2012). Brief postharvest exposure to pulsed light stimulates coloration and anthocyanin accumulation in fig fruit (Ficus carica L.). Postharvest Biology and Technology, 68, 43-46. doi:10.1016/j.postharvbio.2012.02.001

Sjöström, M., Wold, S., Söderström B. (1985). PLS discriminant plots. Proceedings of PARC in Practice, Amsterdam, June 19- 21. North-Holland: Elsevier Science Publishers B.V. 
529 DDP- concerning the marketing and 2013 EDITION.

530 Valadez-Blanco, R., Virdi, a. I. S., Balke, S. T., \& Diosady, L. L. (2007). In-line colour

531 monitoring during food extrusion: Sensitivity and correlation with product colour. Food

532 Research International, 40(9), 1129-1139. doi:10.1016/j.foodres.2007.06.008

533 Vallejo, F., Marín, J. G., \& Tomás-Barberán, F. A. (2012). Phenolic compound content of

534 fresh and dried figs (Ficus carica L.). Food Chemistry, 130(3), 485-492.

535 doi:10.1016/j.foodchem.2011.07.032

536 Vidal, A., Talens, P., Prats-Montalbán, J. M., Cubero, S., Albert, F., \& Blasco, J. (2013). In-

537 Line Estimation of the Standard Colour Index of Citrus Fruits Using a Computer Vision

538 System Developed For a Mobile Platform. Food and Bioprocess Technology, 6(12), 3412-

539 3419. doi:10.1007/s11947-012-1015-2

540 Web references

541 http://agri.istat.it/sag_is_pdwout/jsp/dawinci.jsp?q=plC190000010000032100\&an=2013\&ig=

$5421 \& c t=270 \& i d=15 \mathrm{~A}|21 \mathrm{~A}| 30 \mathrm{~A}$ (accessed on March 31st, 2015)

543 http://faostat3.fao.org/browse/Q/QC/E (accessed on March 30th, 2015)

544 All authors contributed equally to the present work 